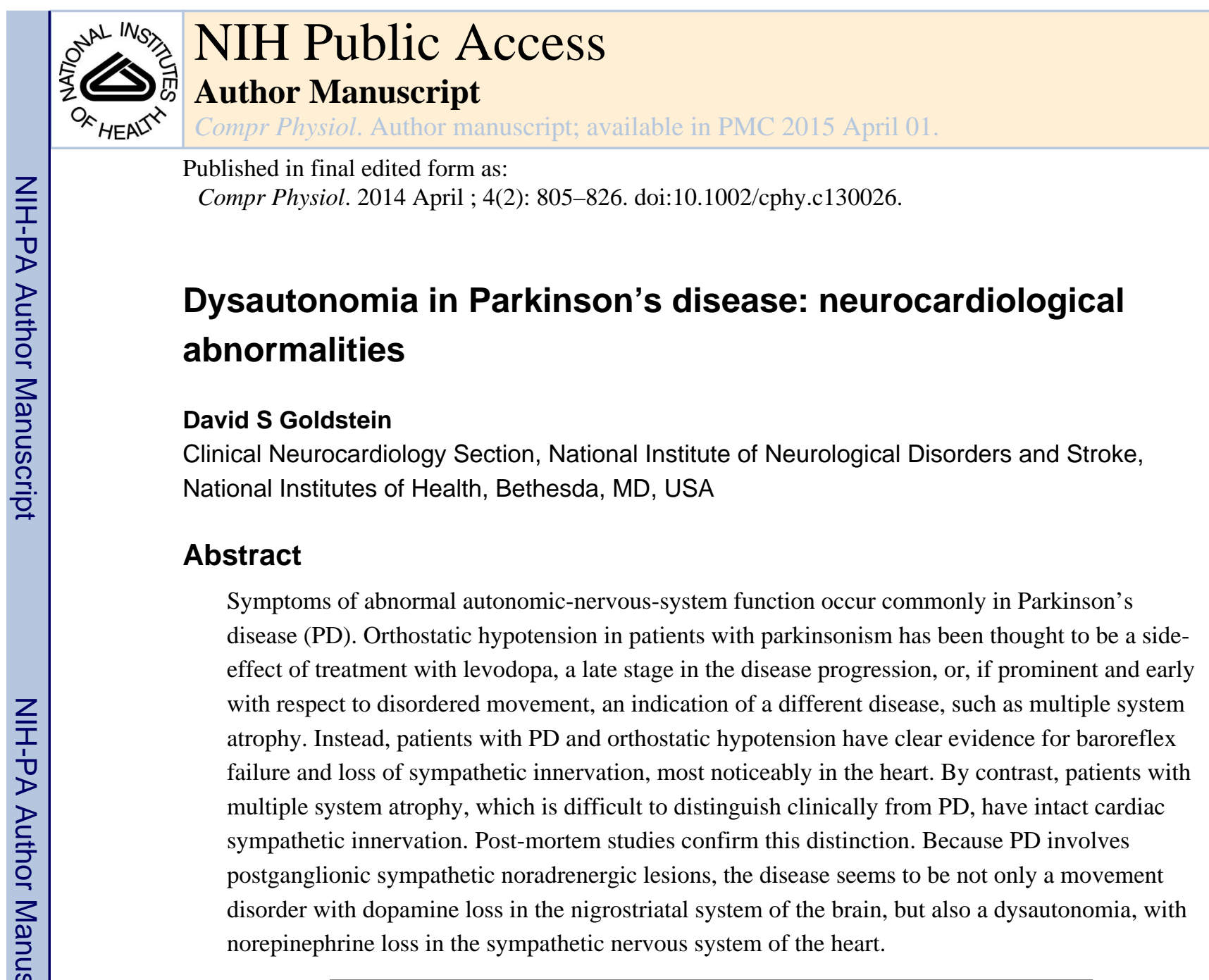

Dysautonomias are disorders in which changes in activity of the autonomic nervous system adversely affect health. ${ }^{1}$ Probably the most common forms of dysautonomia are secondary. The old man who suffers a heart attack while shovelling snow is a classic example: cold exposure, isometric exercise, the morning hours, upright posture, and advancing age combine to increase sympathetic neuronal outflows, which increases myocardial oxygen consumption. Ordinarily, the autonomic changes help maintain homoeostasis; however, in the setting of an independent pathological state-coronary artery stenosis-the increased demand for oxygen delivered via coronary blood flow outstrips the supply, causing ischaemia and arrhythmias.

Less commonly, dysautonomias reflect a primary abnormality of autonomic systems or of regulation of those systems. Both types of primary abnormality seem to occur in Parkinson's disease (PD).

The autonomic nervous system has several components. ${ }^{2}$ Langley, ${ }^{3,4}$ who introduced the term "autonomic nervous system" about a century ago, used it to refer to neurons in ganglia outside the brain and spinal cord that seemed to have functions independent, or autonomous,

Correspondence: Dr David S Goldstein, Building 10, room 6N252, NINDS, NIH, 10 Center Drive, MSC-1620, Bethesda, MD 20892-1620, USA. Tel +1 301496 2103; fax +1 301402 0180; goldsteind@ninds.nih.gov.

Conflict of interest

I have no conflict of interest. 
of the CNS. He proposed three divisions-enteric, sympathetic, and parasympathetic. In the early 20th century, Cannon ${ }^{5,6}$ added an adrenal hormonal component. According to Cannon, the sympathetic nervous system and adrenal gland would act as a unit to maintain homoeostasis (a word Cannon coined) in emergencies. The notion of a unitary "sympathoadrenal" system is generally accepted to this day, despite evidence for differential regulation and dysregulation of sympathetic neuronal and adrenomedullary hormonal effectors. ${ }^{7,8}$ Sweating, whether thermoregulatory, gustatory, or emotional, depends on the delivery of acetylcholine from sympathetic nerves.

The autonomic nervous system therefore contains at least five components-enteric, parasympathetic cholinergic, sympathetic cholinergic, sympathetic noradrenergic, and adrenomedullary hormonal. Failure of a particular component produces characteristic clinical manifestations. Parasympathetic cholinergic failure presents as constipation, dry mouth, a constant pulse rate, urinary retention, and erectile failure in men. Sympathetic cholinergic failure presents as decreased sweating. Sympathetic noradrenergic failure presents as orthostatic intolerance and orthostatic hypotension. Symptoms of autonomic failure in patients with PD include constipation, urinary incontinence, orthostatic or postprandial light-headedness, and heat or cold intolerance, and signs include decreased bowel sounds and orthostatic hypotension. ${ }^{9-14}$ Hence, in PD there seems to be failure or dysregulation of more than one component of the autonomic nervous system.

The past half decade has seen the accumulation of compelling evidence for failure or dysregulation of sympathetic noradrenergic innervation of the cardiovascular system in PD. This review is based on this evidence and on results from our ongoing studies at the National Institutes of Health. ${ }^{15-23}$

Failure or dysregulation of sympathetic noradrenergic innervation is potentially important clinically, because orthostatic hypotension is a cardinal manifestation of sympathetic neurocirculatory failure. Orthostatic hypotension can cause or contribute to susceptibility to falls and other accidental trauma and is treatable. At our institution, orthostatic hypotension is defined as a fall in systolic pressure of $20 \mathrm{~mm} \mathrm{Hg}$ or more and in diastolic pressure of 10 $\mathrm{mm} \mathrm{Hg}$ or more between lying supine for $15 \mathrm{~min}$ and then standing for $5 \mathrm{~min}$. Depending on the definition used and the referral pattern to the assessment centre, orthostatic hypotension occurs in $20-50 \%$ of patients with PD. ${ }^{13,24-26}$

\section{Pure autonomic failure and multiple system atrophy}

Primary chronic autonomic failure has been thought to happen not only in PD but also in two other diseases (figure 1). ${ }^{27,28}$ Pure autonomic failure is severe neurogenic orthostatic hypotension, which is typically caused by generalised sympathetic denervation, without symptoms or signs of central neurodegeneration. In multiple system atrophy, autonomic failure occurs with evidence of central neurodegeneration, subclassified into parkinsonian, cerebellar, or mixed forms.

In pure autonomic failure, the lesion is normally postganglionic, whereas in multiple system atrophy the lesion is preganglionic. Among many findings supporting this distinction, the concentration of norepinephrine in the plasma is low in pure autonomic failure (consistent 
with diffuse sympathetic denervation) but is normal in multiple system atrophy (consistent with ongoing sympathetic nerve traffic). ${ }^{20,29}$ Patients with pure autonomic failure have small changes in blood pressure in response to drugs that decrease or increase release of norepinephrine from sympathetic nerves; the opposite is the case in multiple system atrophy. ${ }^{30-32}$ Studies of the pathology have shown decreased or absent tyrosine hydroxylase in epicardial nerves in pure autonomic failure but normal tyrosine hydroxylase in multiple system atrophy. ${ }^{33-35}$

\section{PD with autonomic failure}

How can one distinguish the parkinsonian form of multiple system atrophy from PD with autonomic failure? About the only way to do so clinically has been to monitor the response to levodopa. In PD, levodopa typically leads to rapid improvement in movement. In multiple system atrophy, however, levodopa produces little or no benefit. In practical terms, this distinction does not always suffice, because some patients with multiple system atrophy do show improvement with levodopa.

Orthostatic hypotension in patients with parkinsonism has been thought to be a side-effect of treatment with levodopa, to develop only late in the disease, or, if prominent and early with respect to disordered movement, to indicate a different disease, such as multiple system atrophy. Instead, irrespective of levodopa treatment and duration of disease, patients with PD and orthostatic hypotension clearly have impaired baroreflex-cardiovagal function and loss of sympathetic innervation diffusely in the left ventricular myocardium. These findings suggest that, in PD, orthostatic hypotension results from the disease process, not the treatment, although drugs that directly or indirectly produce vasodilation can worsen orthostatic tolerance and decrease blood pressure when the patient stands.

\section{Baroreflex failure in PD with orthostatic hypotension}

The arterial baroreflex is a well-studied neurocirculatory reflex. Distortion of stretchsensitive cells in the walls of large arteries and the heart evokes a reflex increase in vagal outflow to the heart, which results in bradycardia, and decreased sympathetic outflow to the cardiovascular system, which results in vasodilation and decreased force of contraction of the heart. Baroreflex-cardiovagal gain is normally calculated from the relation between the interval between heart beats (interbeat interval) and systolic blood pressure after intravenous injection of a vasoconstrictor or vasodilator. ${ }^{36-38}$ For instance, in response to bolus intravenous injection of the a1-adrenoceptor agonist phenylephrine, blood pressure increases, heart rate falls as a reflex to increased vagal outflow to the heart, and the interbeat interval increases. The extent of increase in the interbeat interval for a given increase in blood pressure provides a measure of baroreflex-cardiovagal gain. Analogously, baroreflexsympathoneural gain can be calculated from reflex changes in sympathetic nerve traffic, plasma norepinephrine concentrations, or vascular resistance as the dependent measure. ${ }^{38-45}$

Few studies have assessed baroreflex function in PD. Baroreflex-cardiovagal gain decreases with normal human ageing. ${ }^{46}$ Compared with age-matched controls, patients with PD have low baroreflex-cardiovagal gain. ${ }^{47}$ Only recently has cardiovagal gain been examined in patients with PD stratified by the occurrence of orthostatic hypotension. Baroreflex- 
cardiovagal gain can be estimated from the relation between interbeat interval and systolic blood pressure during phase II of the valsalva manoeuvre (figures 2-4) ${ }^{37}$ In our series, 24 of 26 patients with PD and orthostatic hypotension have had a baroreflex-cardiovagal gain less than $2 \mathrm{~ms} / \mathrm{mm} \mathrm{Hg}$. The mean value, less than $1 \mathrm{~ms} / \mathrm{mm} \mathrm{Hg}$, is far below the average value of about $6 \mathrm{~ms} / \mathrm{mm} \mathrm{Hg}$ in control individuals (normal values in response to a fall in blood pressure can be less than those in response to an increase in blood pressure) ${ }^{21}$ By contrast, among patients with PD who do not have orthostatic hypotension, only about half have had baroreflex-cardiovagal gain less than $2 \mathrm{~ms} / \mathrm{mm} \mathrm{Hg}$, with a mean value of $3.2 \mathrm{~ms} / \mathrm{mm} \mathrm{Hg}$. Thus, in PD without orthostatic hypotension, baroreflex-cardiovagal gain is statistically decreased from normal, but in PD with orthostatic hypotension, baroreflex-cardiovagal gain is very low.

A particular pattern of beat-to-beat blood pressure responses to the valsalva manoeuvre can indicate deficient sympathetic cardiovascular stimulation in response to decreased cardiac filling. ${ }^{17}$ During phase II of the manoeuvre the blood pressure decreases progressively, and during phase IV the pressure does not exceed the baseline value (figure 3). In our series, 24 of 25 patients with PD and orthostatic hypotension have had both abnormalities, and all 25 have had at least one of the two. The orthostatic increment is the proportionate change in a variable between being supine and standing. Most patients with PD have nearly normal or decreased orthostatic increments in the concentration of norepinephrine in the plasma. ${ }^{48-51}$ In patients with $\mathrm{PD}$ and orthostatic hypotension, orthostatic increments in plasma norepinephrine are low. ${ }^{52}$ Thus, in PD, orthostatic hypotension is associated with both baroreflex-cardiovagal and baroreflex-sympathoneural failure.

The site or sites of the central neural lesions that produce baroreflex failure in PD are largely unknown. Although cell loss or Lewy body formation is common in the locus coeruleus, ${ }^{53-58}$ which is the main source of norepinephrine in the brain, and norepinephrine concentrations in the cerebellum, which receives noradrenergic innervation from the locus coeruleus, are low in PD, ${ }^{59}$ and fibres from the locus coeruleus do not descend in the neuraxis to the sympathetic preganglionic neurons. However, $\mathrm{C} 1$ cells of the rostral ventrolateral medulla that contain phenylethanolamine-N-methyltransferase, which catalyses conversion of norepinephrine to epinephrine, do project to sympathetic preganglionic neurons; and some patients with PD have a loss of $\mathrm{C} 1$ cells. ${ }^{60}$ The nucleus of the solitary tract is the main site of termination of baroreceptor afferents. Activity of dopamine $\beta$ hydroxylase, which catalyses conversion of dopamine to norepinephrine, is if anything increased in this tract in PD. ${ }^{61}$ The dorsal motor nucleus of the vagus nerve can have cell loss or Lewy bodies in PD, ${ }^{54,55}$ but the main source of vagal efferents mediating reflexive bradycardia is the nucleus ambiguus, which seems not to be involved in the pathology of PD. 61

\section{Plasma norepinephrine}

Concentrations of norepinephrine in antecubital venous plasma provide a way-albeit indirect- to detect sympathetic denervation in the body as a whole. ${ }^{62}$ Patients with PD and orthostatic hypotension have lower norepinephrine concentrations than those without orthostatic hypotension. ${ }^{21,32,48,52,63,64}$ 
Nevertheless, patients with PD and orthostatic hypotension do not have particularly low norepinephrine concentrations compared with healthy people of similar age, and the concentrations are higher than those in patients with pure autonomic failure (figure 5). Partial loss of sympathetic fibres could lead to increased transmission in the remaining fibres, which results in increased proportionate release of norepinephrine from the reduced vesicular stores. Moreover, because denervation would produce concurrent decreases in both release and reuptake, measurement of norepinephrine concentrations might not detect a real decrease in its release.

Normally, the concentration of norepinephrine in the plasma doubles within 5 min of standing from the supine position. ${ }^{62}$ Most patients with PD without orthostatic hypotension have an increase of $60 \%$ or more in the concentration of norepinephrine in the plasma while standing, whereas nearly all patients with PD and orthostatic hypotension have a smaller increase, consistent with deficient baroreflex-sympathoneural function in the patients with orthostatic hypotension.

\section{Neurocardiological "double hit" in PD with orthostatic hypotension?}

In our study, 22 of 23 patients with PD and orthostatic hypotension have both supine plasma norepinephrine concentration less than $2 \mathrm{nmol} / \mathrm{L}$ and baroreflex-cardiovagal gain less than 2 $\mathrm{ms} / \mathrm{mm} \mathrm{Hg}$, and only six of 15 patients with PD without orthostatic hypotension have both $(\mathrm{p}=0 \cdot 0002) .{ }^{21}$ This combination therefore seems to characterise PD with orthostatic hypotension. Meanwhile, of ten patients with PD and either plasma norepinephrine concentration less than $2 \mathrm{nmol} / \mathrm{L}$ or baroreflex-cardiovagal gain less than $2 \mathrm{~ms} / \mathrm{mm} \mathrm{Hg}$, but not both, only one had orthostatic hypotension.

Baroreflex-sympathoneural failure, indicated by abnormal beat-to-beat blood pressure responses in both phase II and phase IV of the valsalva manoeuvre, combined with a small (less than 60\%) increase in the norepinephrine concentration while standing, has been found in 19 of 25 patients with PD and orthostatic hypotension but in only four of 28 patients with PD without orthostatic hypotension, a highly significant difference $\left(\chi^{2}=20, p<0 \cdot 00001\right)$.

These findings indicate that baroreflex failure, involving both cardiovagal and sympathoneural circuits (a presumably preganglionic lesion), associated with sympathetic denervation (a postganglionic lesion), produces orthostatic hypotension in PD. Baroreflex failure itself does not seem to produce orthostatic hypotension, ${ }^{65,66}$ neither does cardiac sympathetic denervation because patients with cardiac transplants do not have persistent orthostatic hypotension.

\section{Organ-selective sympathetic denervation in PD}

Many studies ${ }^{15,16,19,23,67-82}$ have shown that most patients with PD have at least partial loss of sympathetic innervation of the heart, as indicated by low myocardial concentrations of radioactivity after injection of the sympathoneural imaging agents iodine-123metaiodobenzylguanidine and fluorine-18-labelled dopamine, or by neurochemical assessments during right heart catheterisation. Recent findings of an absence of tyrosine hydroxylase staining in epicardial autopsy samples from patients with PD confirm that 
denervation does occur in the sympathetic nervous system. ${ }^{34,76}$ These findings suggest that, like pure autonomic failure, PD involves a postganglionic lesion, which, in turn, implies that PD is not only a disease of the CNS but also a disease of the autonomic nervous system.

About half of patients with PD without orthostatic hypotension have a loss of ${ }^{18} \mathrm{~F}$-dopa radioactivity diffusely in the left ventricular myocardium, and most of the other patients have loss localised to the lateral or inferior walls, with relative preservation in the septum or anterior wall. Very few patients have entirely normal cardiac ${ }^{18} \mathrm{~F}$-dopa radioactivity (figure 6). ${ }^{19}$ Moreover, the loss of ${ }^{18} \mathrm{~F}$-dopa radioactivity progresses over time. ${ }^{73}$

The extent of sympathetic-innervation loss in PD varies among organs. Normal tissue concentrations of ${ }^{18} \mathrm{~F}$-dopa radioactivity are seen in the liver, spleen, salivary glands, and nasopharyngeal mucosa but low concentrations are seen in the thyroid gland and renal cortex. ${ }^{15,19}$ Studies with ${ }^{123}$ I-meta-iodobenzylguanidine have shown decreased radioactivity only in the heart. ${ }^{74,78,82}$ Concentrations of norepinephrine in the plasma in PD with orthostatic hypotension are about the same as those in multiple system atrophy with orthostatic hypotension during supine rest and standing, and are higher than those in patients with pure autonomic failure.

There have been several reports about the status of cutaneous sympathetic innervation in PD. ${ }^{83-89}$ Most of these reports have relied on measurements of skin humidity or electrical conductance. These provide indices of sweat production, which depends on sympathetic cholinergic innervation. Moreover, abnormal results could reflect dysregulation of sympathetic outflow to intact terminals. The results have been variable. Patients with PD and orthostatic hypotension have intact sympathetic cholinergic innervation, as measured by the quantitative sudomotor axon reflex test, despite sympathetic neurocirculatory failure. ${ }^{22}$ A case report noted decreased cutaneous vasoconstrictor responses, assessed by laserdoppler flow analysis, in a patient with autonomic failure and uncomplicated PD. ${ }^{90}$ The report did not distinguish dysregulation from denervation.

Why sympathetic denervation in PD is heterogeneous among body organs and why the denervation is so prominent in the heart are unknown.

\section{Does levodopa cause orthostatic hypotension?}

If levodopa were the only cause of orthostatic hypotension in PD, a higher proportion of patients with orthostatic hypotension would be on levodopa therapy than would patients without orthostatic hypotension. Recent work has failed to support this prediction. ${ }^{19,21}$ Patients with PD and orthostatic hypotension actually do not differ from those without orthostatic hypotension, in terms of either the frequency of levodopa treatment or the concentrations of levodopa in the plasma. Perhaps most convincingly, orthostatic hypotension can occur in patients with PD who have never taken levodopa or discontinued levodopa treatment in the remote past.

Even with carbidopa treatment, which attenuates conversion of levodopa to dopamine outside the CNS, levodopa increases concentrations of both dopamine and its deaminated metabolite dihydroxyphenylacetic acid in the plasma. Although dopamine infused at high 
doses is a pressor agent, at low doses dopamine produces vasodilation, by stimulating dopamine D1 receptors on vascular smooth muscle cells and possibly by stimulating inhibitory dopamine D2 receptors and thereby decreasing norepinephrine release from sympathetic nerves. ${ }^{91}$ Dopamine also augments natriuresis and diuresis, which promotes depletion of extracellular fluid and blood volumes. Therefore, in the setting of decreased cardiovascular sympathetic innervation and baroreflex failure, vasodilation and hypovolaemia caused by the dopamine produced from levodopa might decrease the blood pressure, both during supine rest and during standing, in patients with PD. Thus, orthostatic intolerance and orthostatic hypotension may occur in patients with PD while taking levodopa or dopamine receptor agonists, not directly from effects of these drugs alone but from interactions with baroreflex and sympathoneural pathophysiological mechanisms that are part of the disease process.

\section{Absence of postganglionic lesion in multiple system atrophy}

Perhaps as remarkable as the finding that all patients with PD and orthostatic hypotension have cardiac sympathetic denervation is that all patients with multiple system atrophy, with or without orthostatic hypotension, have intact cardiac sympathetic innervation, as measured by sympathetic neuroimaging and normal or even increased rates of entry of norepinephrine, and other catecholamines into coronary sinus plasma (figure 7). ${ }^{15,16,19,69,70.74,76,77}$

Validation of the differential diagnoses of PD and multiple system atrophy, based on the occurrence of cardiac sympathetic denervation in the former but not the latter, requires a standard, such as autopsy pathology, that unequivocally distinguishes these diseases. Two recent studies have provided this important evidence. ${ }^{34,76}$ All patients with autonomic failure, central neurodegeneration, and decreased cardiac ${ }^{123}$ I-metaiodobenzylguanidine radioactivity who have been studied after death have had nigrostriatal Lewy bodies pathognomonic of $\mathrm{PD}$, and absent immunoreactive tyrosine hydroxylase in the epicardium, which suggests sympathetic noradrenergic denervation. All patients with normal cardiac ${ }^{123}$ I-metaiodobenzylguanidine radioactivity have had no nigrostriatal Lewy bodies, have had glial cytoplasmic inclusions (thought to be characteristic of multiple system atrophy) and normal immunoreactive tyrosine hydroxylase. According to a proposed pathophysiological classification of primary chronic autonomic failure (figure 8), PD with autonomic failure features a postganglionic, sympathetic, noradrenergic lesion, whereas the parkinsonian form of multiple system atrophy does not.

\section{Denervation supersensitivity}

Clinical and preclinical studies of chronic autonomic failure have consistently noted increased blood pressure or vasoconstrictor responses to exogenously given adrenergicreceptor agonists in PD with orthostatic hypotension. ${ }^{63,77,92}$ This finding probably reflects "denervation supersensitivity", as described by Cannon. ${ }^{93}$ Mechanisms of sympathetic denervation supersensitivity are not fully understood. The disorder probably results from increased presentation of adrenoceptors to the cell membrane of cardiovascular smooth muscle cells, high adrenoceptor synthesis, or changes to intracellular signalling after 
receptor occupation. Cardiac sympathetic denervation supersensitivity may predispose to the development of arrhythmias. ${ }^{94,95}$

Strong cardiovascular responses to adrenoceptor agonists could have other explanations, such as decreased baroreflex buffering of sympathetic outflows, which seems to characterise PD with orthostatic hypotension. Structural adaptations of vascular walls, with increases in the ratio of wall to lumen, are common in hypertension, and supine hypertension commonly seems to associate with orthostatic hypotension in patients with autonomic failure. Thus, researchers have noted augmented pressor responses to exogenously given norepinephrine, with the augmentation seen mainly, or only, in patients with PD and orthostatic hypotension. These results do not necessarily imply that PD with orthostatic hypotension features denervation supersensitivity.

\section{Clinical implications}

Neurocirculatory dysregulation in PD with orthostatic hypotension has several clinical implications. Doctors face the dilemma of trying to decrease morbidity from orthostatic hypotension, where the treatment typically worsens supine hypertension. The risks of supine hypertension in this setting are largely statistical and long-term, whereas those of orthostatic hypotension are real and immediate. Therefore, at our centre, we set a goal of a systolic blood pressure while standing of at least $100 \mathrm{~mm} \mathrm{Hg}$, in the morning, because in autonomic failure the blood pressure tends to rise throughout the day. Patients should take frequent small meals to minimise hypotension after eating. If patients plan to exercise, especially in the heat, they should drink water that contains some salt before. Immersion in a hot tub or whirlpool is out of the question. Because drugs that cause vasodilation can worsen orthostatic hypotension and evoke orthostatic presyncope, the patient must review with a knowledgeable physician all ingested substances, whether prescribed drugs, over-thecounter drugs, herbal remedies, dietary supplements, or special diets. Finally, although research on the topic is scant, the anecdotal experience at our institution so far indicates that neurosurgical treatments for the movement disorder do not improve baroreflex function, sympathetic innervation, or orthostatic hypotension in PD.

\section{Conclusions}

Loss of sympathetic nerves and subsequent failure of baroreflex can explain orthostatic hypotension in PD. Hypotension during standing or after a large meal can worsen during treatment with levodopa, dopamine-receptor agonists, or any vasodilator or diuretic agent. Cardiac sympathetic denervation characterises most patients with PD and all patients with PD and orthostatic hypotension. These findings contrast with those in multiple system atrophy.

The functional consequences of cardiac sympathetic denervation in PD are unknown. Cardiac sympathetic denervation might manifest clinically as shortness of breath during exercise and a tendency to fatigue. Whether cardiac sympathetic denervation predisposes to arrhythmias, the relation between central dopaminergic and peripheral noradrenergic 
pathologies, and bases for organ-selective sympathetic denervation in PD are also all unknown.

\section{Acknowledgments}

The work was funded by the National Institute of Neurological Disorders and Stroke, National Institute of Health.

Role of the funding source

No funding bodies had a role in the preparation of this review or the decision to submit it for publication.

\section{References}

1. Goldstein D, Eisenhofer G, Robertson D, Straus R, Esler M. Dysautonomias: clinical disorders of the autonomic nervous system. Ann Intern Med. 2002; 137:753-63. [PubMed: 12416949]

2. Goldstein, DS. The autonomic nervous system in health and disease. Marcel Dekker Inc; New York: 2001.

3. Langley JN. The autonomic nervous system. Brain. 1903; 26:1-26.

4. Langley, JN. W Heffer and Sons Ltd; Cambridge: 1921. The autonomic nervous system.

5. Cannon WB. The emergency function of the adrenal medulla in pain and in the major emotions. Am J Physiol. 1914; 33:356-72.

6. Cannon, WB. The Wisdom of the body. WW Norton; New York: 1939.

7. Pacak K, Palkovits M, Yadid G, Kvetnansky R, Kopin IJ, Goldstein DS. Heterogeneous neurochemical responses to different stressors: a test of Selye's doctrine of nonspecificity. Am J Physiol. 1998; 275:R1247-55. [PubMed: 9756557]

8. Young JB, Rosa RM, Landsberg L. Dissociation of sympathetic nervous system and adrenal medullary responses. Am J Physiol. 1984; 247:E35-40. [PubMed: 6742188]

9. Appenzeller O, Goss JE. Autonomic deficits in Parkinson's syndrome. Arch Neurol. 1971; 24:5057. [PubMed: 5539987]

10. Rajput AH, Rozdilsky B. Dysautonomia in Parkinsonism: a clinicopathological study. J Neurol Neurosurg Psychiatry. 1976; 39:1092-100. [PubMed: 188990]

11. Takahashi A. Autonomic nervous system disorders in Parkinson's disease. Eur Neurol. 1991; 31(suppl 1):41-47. [PubMed: 1855522]

12. Martignoni E, Pacchetti C, Godi L, Micieli G, Nappi G. Autonomic disorders in Parkinson's disease. J Neural Transm Suppl. 1995; 45:11-19. [PubMed: 8748604]

13. Micieli G, Martignoni E, Cavallini A, Sandrini G, Nappi G. Postprandial and orthostatic hypotension in Parkinson's disease. Neurology. 1987; 37:386-93. [PubMed: 3822130]

14. Mathias CJ. Cardiovascular autonomic dysfunction in parkinsonian patients. Clin Neurosci. 1998; 5:153-66. [PubMed: 10785842]

15. Goldstein DS, Holmes C, Li ST, Bruce S, Metman LV, Cannon RO. Cardiac sympathetic denervation in Parkinson disease. Ann Intern Med. 2000; 133:338-47. [PubMed: 10979878]

16. Goldstein DS, Holmes C, Cannon RO III, Eisenhofer G, Kopin IJ. Sympathetic cardioneuropathy in dysautonomias. N Engl J Med. 1997; 336:696-702. [PubMed: 9041100]

17. Goldstein DS, Tack C. Non-invasive detection of sympathetic neurocirculatory failure. Clin Auton Res. 2000; 10:285-91. [PubMed: 11198484]

18. Goldstein DS, Li S-T, Kopin IJ. Sympathetic neurocirculatory failure in Parkinson disease: evidence for an etiologic role of a-synuclein. Ann Intern Med. 2001; 135:1010-11. [PubMed: 11730415]

19. Goldstein DS, Holmes C, Dendi R, Bruce S, Li S-T. Orthostatic hypotension from sympathetic denervation in Parkinson's disease. Neurology. 2002; 58:1247-55. [PubMed: 11971094]

20. Goldstein DS, Holmes C, Sharabi Y, Brentzel S, Eisenhofer G. Plasma levels of catechols and metanephrines in neurogenic orthostatic hypotension. Neurology. 2003; 60:1327-32. [PubMed: 12707437] 
21. Goldstein DS, Pechnik S, Holmes C, Eldadah B, Sharabi Y. Association between supine hypertension and orthostatic hypotension in autonomic failure. Hypertension. 2003; 42:136-42. [PubMed: 12835329]

22. Sharabi Y, Li ST, Dendi R, Holmes C, Goldstein DS. Neurotransmitter specificity of sympathetic denervation in Parkinson's disease. Neurology. 2003; 60:1036-39. [PubMed: 12654979]

23. Li ST, Dendi R, Holmes C, Goldstein DS. Progressive loss of cardiac sympathetic innervation in Parkinson's disease. Ann Neurol. 2002; 52:220-23. [PubMed: 12210793]

24. Senard JM, Rai S, Lapeyre-Mestre M, et al. Prevalence of orthostatic hypotension in Parkinson's disease. J Neurol Neurosurg Psychiatry. 1997; 63:584-89. [PubMed: 9408097]

25. Cardiovascular disorders in Parkinson disease are underrated. Fortschr Neurol Psychiatr. 1999; 67:A8-A9. [PubMed: 10683748]

26. Hillen ME, Wagner ML, Sage JI. "Subclinical” orthostatic hypotension is associated with dizziness in elderly patients with Parkinson disease. Arch Phys Med Rehabil. 1996; 77:710-12. [PubMed: 8670000]

27. Gilman S, Low P, Quinn N, et al. Consensus statement on the diagnosis of multiple system atrophy. Clin Auton Res. 1998; 8:359-62. [PubMed: 9869555]

28. Mathias CJ. The classification and nomenclature of autonomic disorders: ending chaos, resolving conflict and hopefully achieving clarity. Clin Auton Res. 1995; 5:307-10. [PubMed: 8601078]

29. Goldstein DS, Polinsky RJ, Garty M, et al. Patterns of plasma levels of catechols in neurogenic orthostatic hypotension. Ann Neurol. 1989; 26:558-63. [PubMed: 2510587]

30. Polinsky, RJ. Neuropharmacological investigation of autonomic failure. In: Bannister, R.; Mathias, CJ., editors. Autonomic failure. Oxford University Press; New York: 1992. p. 334-58.

31. Jordan J, Shannon JR, Biaggioni I, Norman R, Black BK, Robertson D. Contrasting actions of pressor agents in severe autonomic failure. Am J Med. 1998; 105:116-24. [PubMed: 9727818]

32. Senard JM, Rascol O, Durrieu G, et al. Effects of yohimbine on plasma catecholamine levels in orthostatic hypotension related to Parkinson disease or multiple system atrophy. Clin Neuropharmacol. 1993; 16:70-76. [PubMed: 8422659]

33. Hague K, Lento P, Morgello S, Caro S, Kaufmann H. The distribution of Lewy bodies in pure autonomic failure: autopsy findings and review of the literature. Acta Neuropathol (Berl). 1997; 94:192-96. [PubMed: 9255396]

34. Orimo S, Oka T, Miura H, et al. Sympathetic cardiac denervation in Parkinson's disease and pure autonomic failure but not in multiple system atrophy. J Neurol Neurosurg Psychiatry. 2002; 73:776-77. [PubMed: 12438492]

35. Black IB, Petito CK. Catecholamine enzymes in the degenerative neurological disease idiopathic orthostatic hypotension. Science. 1976; 192:910-12. [PubMed: 5774]

36. Smyth HS, Sleight P, Pickering GW. Reflex regulation of arterial pressure during sleep in man: quantitative method of assessing baroreflex sensitivity. Circ Res. 1969; 24:109-21. [PubMed: 4303309]

37. Goldstein DS, Horwitz D, Keiser HR. Comparison of techniques for measuring baroreflex sensitivity in man. Circulation. 1982; 66:432-39. [PubMed: 7094250]

38. Jacobsen TN, Morgan BJ, Scherrer U, et al. Relative contributions of cardiopulmonary and sinoaortic baroreflexes in causing sympathetic activation in the human skeletal muscle circulation during orthostatic stress. Circ Res. 1993; 73:367-78. [PubMed: 8330379]

39. Davy KP, Seals DR, Tanaka H. Augmented cardiopulmonary and integrative sympathetic baroreflexes but attenuated peripheral vasoconstriction with age. Hypertension. 1998; 32:298-304. [PubMed: 9719058]

40. Ebert TJ, Morgan BJ, Barney JA, Denahan T, Smith JJ. Effects of aging on baroreflex regulation of sympathetic activity in humans. Am J Physiol. 1992; 263:H798-803. [PubMed: 1415605]

41. Mark AL, Kerber RE. Augmentation of cardiopulmonary baroreflex control of forearm vascular resistance in borderline hypertension. Hypertension. 1982; 4:39-46. [PubMed: 7061127]

42. Matsukawa T, Sugiyama Y, Mano T. Age-related changes in baroreflex control of heart rate and sympathetic nerve activity in healthy humans. J Auton Nerv Syst. 1996; 60:209-12. [PubMed: 8912273] 
43. O’Mahony D, Bennett C, Green A, Sinclair AJ. Reduced baroreflex sensitivity in elderly humans is not due to efferent autonomic dysfunction. Clin Sci. 2000; 98:103-10. [PubMed: 10600664]

44. Sanders JS, Mark AL, Ferguson DW. Importance of aortic baroreflex in regulation of sympathetic responses during hypotension: evidence from direct sympathetic nerve recordings in humans. Circulation. 1989; 79:83-92. [PubMed: 2910547]

45. Shimada K, Kitazumi T, Sadakane N, Ogura H, Ozawa T. Age-related changes of baroreflex function, plasma norepinephrine, and blood pressure. Hypertension. 1985; 7:113-17. [PubMed: 3980053]

46. Bristow JD, Honour J, Pickering GW, Sleight P, Smyth HS. Diminished baroreflex sensitivity in high blood pressure. Circulation. 1969; 39:48-54. [PubMed: 4302539]

47. Szili-Torok T, Kalman J, Paprika D, Dibo G, Rozsa Z, Rudas L. Depressed baroreflex sensitivity in patients with Alzheimer's and Parkinson's disease. Neurobiol Aging. 2001; 22:435-38. [PubMed: 11378250]

48. Turkka JT. Correlation of the severity of autonomic dysfunction to cardiovascular reflexes and to plasma noradrenaline levels in Parkinson's disease. Eur Neurol. 1987; 26:203-10. [PubMed: 3595658]

49. Durrieu G, Senard JM, Rascol O, et al. Blood pressure and plasma catecholamines in never-treated parkinsonian patients: effect of a selective D1 agonist (CY 208-243). Neurology. 1990; 40:70709. [PubMed: 2320249]

50. Turkka JT, Juujarvi KK, Lapinlampi TO, Myllyla VV. Serum norepinephrine response to standing in patients with Parkinson's disease. Adv Neurol. 1987; 45:259-61. [PubMed: 3825698]

51. Quadri R, Comino I, Scarzella L, et al. Autonomic nervous function in de novo parkinsonian patients in basal condition and after acute levodopa administration. Funct Neurol. 2000; 15:81-86. [PubMed: 10916719]

52. Niimi Y, Ieda T, Hirayama M, et al. Clinical and physiological characteristics of autonomic failure with Parkinson's disease. Clin Auton Res. 1999; 9:139-44. [PubMed: 10454060]

53. Zweig RM, Cardillo JE, Cohen M, Giere S, Hedreen JC. The locus ceruleus and dementia in Parkinson's disease. Neurology. 1993; 43:986-91. [PubMed: 8492957]

54. Wakabayashi K, Toyoshima Y, Awamori K, et al. Restricted occurrence of Lewy bodies in the dorsal vagal nucleus in a patient with late-onset parkinsonism. J Neurol Sci. 1999; 165:188-91. [PubMed: 10450807]

55. Jellinger KA. Pathology of Parkinson's disease. Changes other than the nigrostriatal pathway. Mol Chem Neuropathol. 1991; 14:153-97. [PubMed: 1958262]

56. Halliday GM, Li YW, Blumbergs PC, et al. Neuropathology of immunohistochemically identified brainstem neurons in Parkinson's disease. Ann Neurol. 1990; 27:373-85. [PubMed: 1972319]

57. Freed DM. On the involvement of the locus ceruleus in Parkinson's disease. J Neuropsychiatry Clin Neurosci. 1990; 2:114-15. [PubMed: 2136056]

58. Forno LS, Alvord EC Jr. Depigmentation in the nerve cells of the substantia nigra and locus ceruleus in Parkinsonism. Adv Neurol. 1974; 5:195-202. [PubMed: 4374062]

59. Kish SJ, Shannak KS, Rajput AH, Gilbert JJ, Hornykiewicz O. Cerebellar norepinephrine in patients with Parkinson's disease and control subjects. Arch Neurol. 1984; 41:612-14. [PubMed: 6721735]

60. Gai WP, Geffen LB, Denoroy L, Blessing WW. Loss of C1 and C3 epinephrine-synthesizing neurons in the medulla oblongata in Parkinson's disease. Ann Neurol. 1993; 33:357-67. [PubMed: 8489206]

61. Benarroch EE, Schmeichel AM, Parisi JE. Preservation of branchimotor neurons of the nucleus ambiguus in multiple system atrophy. Neurology. 2003; 60:115-17. [PubMed: 12525730]

62. Lake CR, Ziegler MG, Kopin IJ. Use of plasma norepinephrine for evaluation of sympathetic neuronal function in man. Life Sci. 1976; 18:1315-25. [PubMed: 933720]

63. Senard JM, Valet P, Durrieu G, et al. Adrenergic supersensitivity in parkinsonians with orthostatic hypotension. Eur J Clin Invest. 1990; 20:613-19. [PubMed: 1964123]

64. Galinier M, Senard JM, Valet P, et al. Relationship between arterial blood pressure disturbances and alpha adrenoceptor density. Clin Exp Hypertens. 1994; 16:373-89. [PubMed: 8038761] 
65. Robertson D, Hollister AS, Biaggioni I, Netterville JL, Mosqueda-Garcia R, Robertson RM. The diagnosis and treatment of baroreflex failure. N Engl J Med. 1993; 329:1449-55. [PubMed: 8413455]

66. Robertson D, Hollister AS, Biaggioni I. Arterial baroreflex failure in man. Clin Auton Res. 1993; $3: 212$.

67. Satoh A, Serita T, Tsujihata M. Total defect of metaiodobenzylguanidine (MIBG) imaging on heart in Parkinson's disease: assessment of cardiac sympathetic denervation. Nippon Rinsho. 1997; 55:202-06. [PubMed: 9014450]

68. Satoh A, Serita T, Seto M, et al. Loss of 123I-MIBG uptake by the heart in Parkinson's disease: assessment of cardiac sympathetic denervation and diagnostic value. J Nucl Med. 1999; 40:37175. [PubMed: 10086697]

69. Druschky A, Hilz MJ, Platsch G, et al. Differentiation of Parkinson's disease and multiple system atrophy in early disease stages by means of I-123-MIBG-SPECT. J Neurol Sci. 2000; 175:3-12. [PubMed: 10785250]

70. Braune S, Reinhardt M, Schnitzer R, Riedel A, Lucking CH. Cardiac uptake of [123I]MIBG separates Parkinson's disease from multiple system atrophy. Neurology. 1999; 53:1020-25. [PubMed: 10496261]

71. Yoshita M, Hayashi M, Hirai S. Decreased myocardial accumulation of 123I-meta-iodobenzyl guanidine in Parkinson's disease. Nucl Med Commun. 1998; 19:137-42. [PubMed: 9548197]

72. Kanzaki N, Sato K, Hayabara T. Improved cardiac iodine-123 metaiodobenzylguanidine accumulation after drug therapy in a patient with Parkinson's disease. Clin Nucl Med. 1997; 22:697-99. [PubMed: 9343727]

73. Ohmura M. Loss of 123I-MIBG uptake by the heart in Parkinson's disease: assessment of cardiac sympathetic denervation and diagnostic value. J Nucl Med. 2000; 41:1594-95. [PubMed: 10994743]

74. Reinhardt MJ, Jungling FD, Krause TM, Braune S. Scintigraphic differentiation between two forms of primary dysautonomia early after onset of autonomic dysfunction: value of cardiac and pulmonary iodine-123 MIBG uptake. Eur J Nucl Med. 2000; 27:595-600. [PubMed: 10853817]

75. Braune S, Reinhardt M, Bathmann J, Krause T, Lehmann M, Lucking CH. Impaired cardiac uptake of meta-[123I]iodobenzylguanidine in Parkinson's disease with autonomic failure. Acta Neurol Scand. 1998; 97:307-14. [PubMed: 9613560]

76. Orimo S, Ozawa E, Oka T, et al. Different histopathology accounting for a decrease in myocardial MIBG uptake in PD and MSA. Neurology. 2001; 57:1140-41. [PubMed: 11571358]

77. Senard JM, Brefel-Courbon C, Rascol O, Montastruc JL. Orthostatic hypotension in patients with Parkinson's disease: pathophysiology and management. Drugs Aging. 2001; 18:495-505. [PubMed: 11482743]

78. Takatsu H, Nishida H, Matsuo H, et al. Cardiac sympathetic denervation from the early stage of Parkinson's disease: clinical and experimental studies with radiolabeled MIBG. J Nucl Med. 2000; 41:71-77. [PubMed: 10647607]

79. Orimo S, Ozawa E, Nakade S, Sugimoto T, Mizusawa H. (123)I-metaiodobenzylguanidine myocardial scintigraphy in Parkinson's disease. J Neurol Neurosurg Psychiatry. 1999; 67:189-94. [PubMed: 10406987]

80. Yoshita M, Hayashi M, Hirai S. Iodine 123-labeled meta-iodobenzylguanidine myocardial scintigraphy in the cases of idiopathic Parkinson's disease, multiple system atrophy, and progressive supranuclear palsy. Rinsho Shinkeigaku. 1997; 37:476-82. [PubMed: 9366173]

81. Akincioglu C, Unlu M, Tunc T. Cardiac innervation and clinical correlates in idiopathic Parkinson's disease. Nucl Med Commun. 2003; 24:267-71. [PubMed: 12612467]

82. Taki J, Nakajima K, Hwang EH, et al. Peripheral sympathetic dysfunction in patients with Parkinson's disease without autonomic failure is heart selective and disease specific. Eur J Nucl Med. 2000; 27:566-73. [PubMed: 10853813]

83. De Marinis M, Stocchi F, Gregori B, Accornero N. Sympathetic skin response and cardiovascular autonomic function tests in Parkinson's disease and multiple system atrophy with autonomic failure. Mov Disord. 2000; 15:1215-20. [PubMed: 11104208] 
84. Haapaniemi TH, Korpelainen JT, Tolonen U, Suominen K, Sotaniemi KA, Myllyla VV. Suppressed sympathetic skin response in Parkinson disease. Clin Auton Res. 2000; 10:337-42. [PubMed: 11324989]

85. Choi BO, Bang OY, Sohn YH, Sunwoo IN. Sympathetic skin response and cardiovascular autonomic function tests in Parkinson's disease. Yonsei Med J. 1998; 39:439-45. [PubMed: 9821793]

86. Braune HJ, Korchounov AM, Schipper HI. Autonomic dysfunction in Parkinson's disease assessed by sympathetic skin response: a prospective clinical and neurophysiological trial on 50 patients. Acta Neurol Scand. 1997; 95:293-97. [PubMed: 9188905]

87. Denislic M, Meh D. Sympathetic skin response in parkinsonian patients. Electromyogr Clin Neurophysiol. 1996; 36:231-35. [PubMed: 8803495]

88. Hirashima F, Yokota T, Hayashi M. Sympathetic skin response in Parkinson's disease. Acta Neurol Scand. 1996; 93:127-32. [PubMed: 8741131]

89. Wang SJ, Fuh JL, Shan DE, et al. Sympathetic skin response and R-R interval variation in Parkinson's disease. Mov Disord. 1993; 8:151-57. [PubMed: 8474481]

90. Baron R, Feldmann R, Lindner V. Small fibre function in primary autonomic failure. J Neurol. 1993; 241:87-91. [PubMed: 8138830]

91. Murphy MB. Dopamine: a role in the pathogenesis and treatment of hypertension. J Hum Hypertens. 2000; 14(suppl 1):S47-50. [PubMed: 10854081]

92. Galinier M, Senard JM, Valet P, et al. Relationship between arterial blood pressure disturbances and alpha adrenoceptor density. Clin Exp Hypertens. 1994; 16:373-89. [PubMed: 8038761]

93. Cannon WB. A law of denervation. Am J Med Sci. 1939; 198:737-50.

94. Inoue H, Zipes DP. Results of sympathetic denervation in the canine heart: supersensitivity that may be arrhythmogenic. Circulation. 1987; 75:877-87. [PubMed: 3829345]

95. Mitrani RD, Klein LS, Miles WM, et al. Regional cardiac sympathetic denervation in patients with ventricular tachycardia in the absence of coronary artery disease. J Am Coll Cardiol. 1993; 22:1344-53. [PubMed: 8227790] 

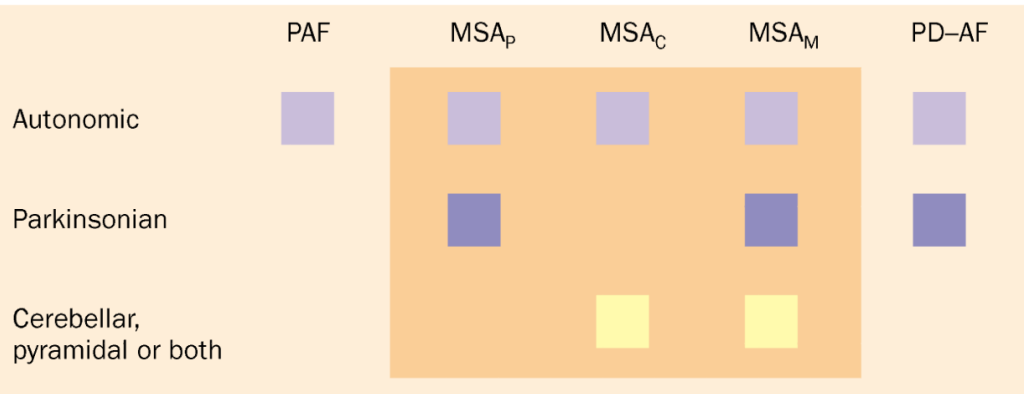

Figure 1.

Clinical classification of primary chronic autonomic failure. Pure autonomic failure (PAF) features autonomic failure without evidence of central neurodegeneration. Multiple system atrophy (MSA) has parkinsonian, cerebellar, and mixed forms. PD with autonomic failure (PD-AF) can be difficult to distinguish clinically from the parkinsonian form of MSA. 


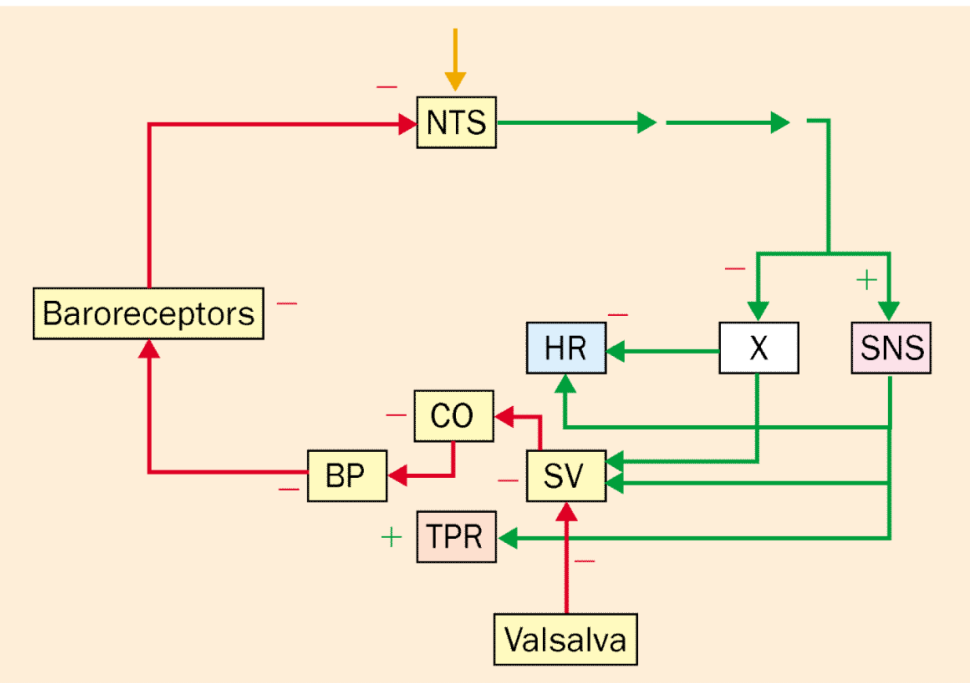

Figure 2.

Reflexive responses to the Valsalva manoeuvre. Afferents are shown in red and efferents in green. During the manoeuvre, venous return to the heart decreases, and cardiac stroke volume (SV) and output (CO) fall as does blood pressure (BP). Afferent nerve traffic to the nucleus of the solitary tract (NTS) from arterial and cardiopulmonary baroreceptors declines. Efferent activity in the vagus nerve $(\mathrm{X})$ decreases reflexively, increasing heart rate (HR), and efferent activity in the sympathetic nervous system (SNS) increases reflexively, increasing total peripheral resistance (TPR). -=inhibition; +=stimulation. 


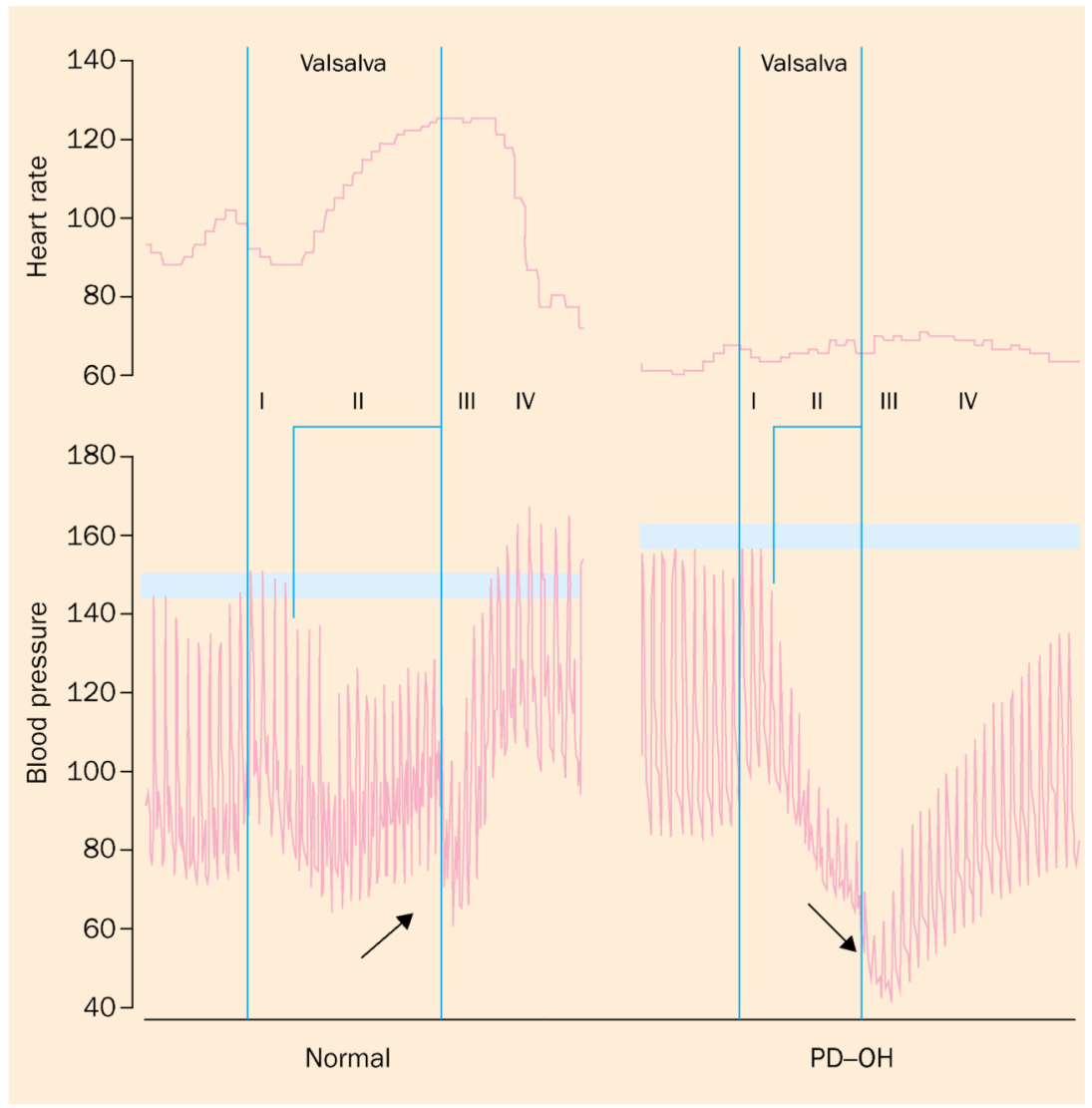

Figure 3

. Blood pressure and heart rate during the Valsalva manoeuvre. In phase II, blood pressure normally increases from its lowest, and in phase IV blood pressure overshoots baseline. In $\mathrm{PD}$ with orthostatic hypotension (PD-OH), blood pressure decreases progressively in phase II and fails to overshoot the baseline pressure in phase IV, which are signs of sympathetic neurocirculatory or baroreflex-sympathoneural failure. PD-OH also features baroreflexcardiovagal failure, manifested by constant interbeat interval despite arterial hypotension. 


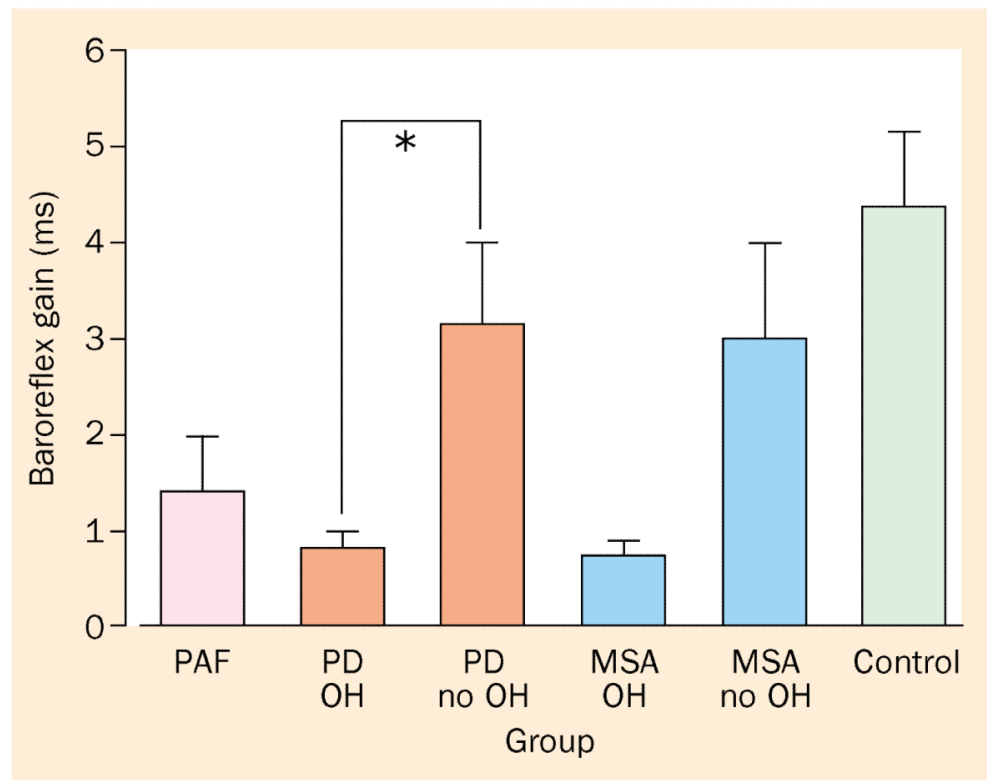

Figure 4.

Baroreflex-cardiovagal gain in pure autonomic failure (PAF), PD with or without orthostatic hypotension $(\mathrm{OH})$, and multiple system atrophy (MSA) with or without $\mathrm{OH}$. All three forms of chronic primary autonomic failure feature extremely low baroreflex-cardiovagal gain. 


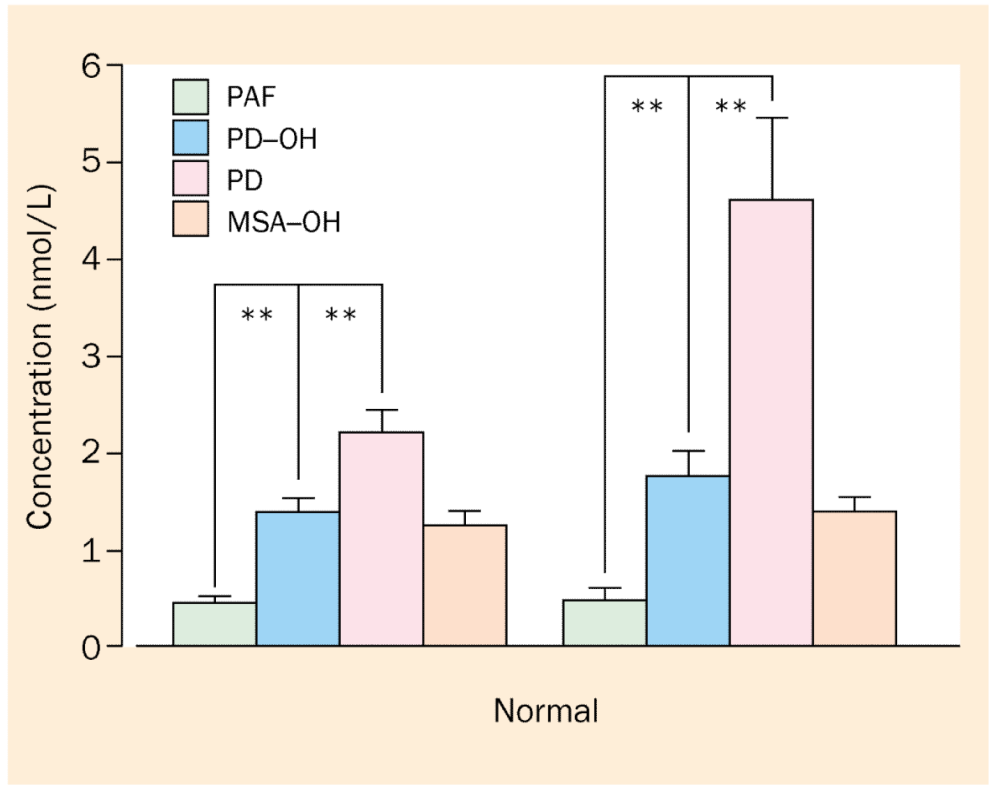

Figure 5.

Concentrations of norepinephrine in the plasma during supine rest and after 5 min of standing in patients with pure autonomic failure (PAF), PD with or without orthostatic hypotension $(\mathrm{OH})$, and multiple system atrophy (MSA) with $\mathrm{OH}$. Note blunted orthostatic increment in plasma noradrenaline concentration in PAF, PD-OH, and MSA-OH but not in $\mathrm{PD}$ without $\mathrm{OH}$. 


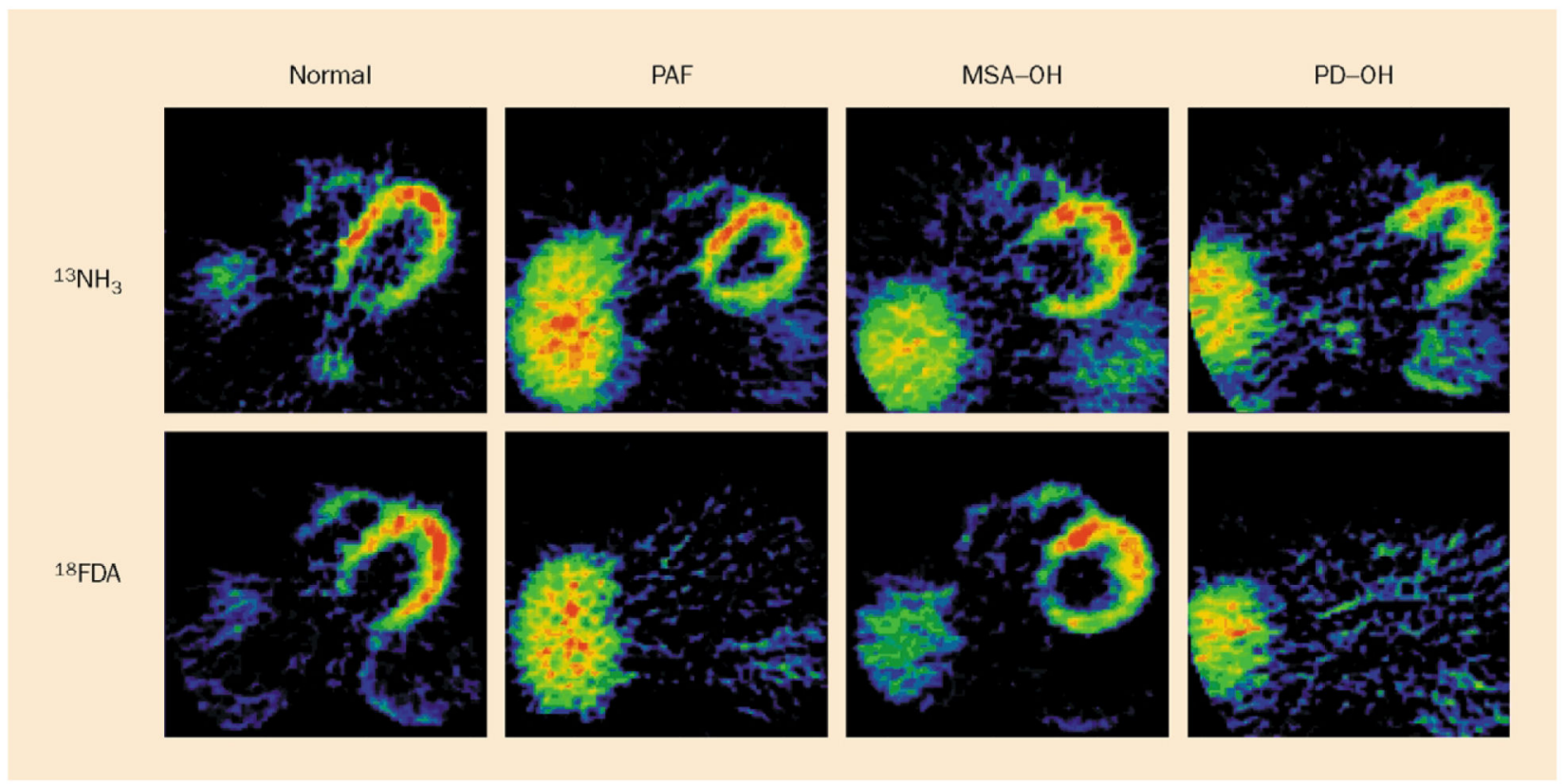

Figure 6.

Cardiac PET scans in a control subject and in patients with pure autonomic failure (PAF), multiple system atrophy with orthostatic hypotension (MSA-OH), and PD with orthostatic hypotension (PD-OH). Top: nitrogen-13-labelled ammonia $\left({ }^{13} \mathrm{NH}_{3}\right)$ perfusion scans. Bottom: ${ }^{18}$ F-dopa $\left({ }^{18}\right.$ FDA) sympathoneural scans in each patient. Note absence of cardiac ${ }^{18} \mathrm{~F}$-dopa imaging in $\mathrm{PAF}$ and $\mathrm{PD}-\mathrm{OH}$ and normal radioactivity in MSA-OH. 

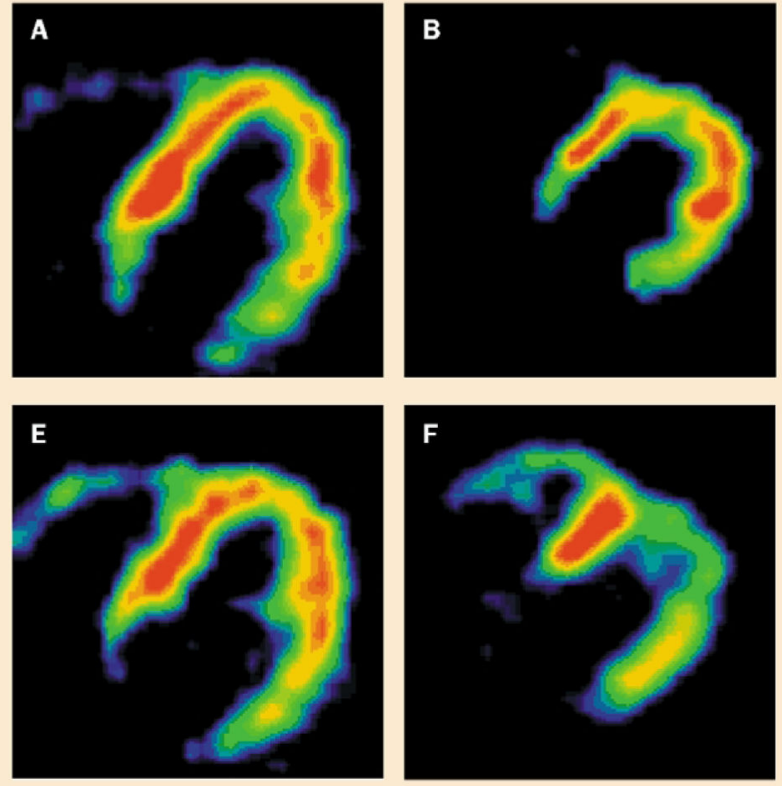
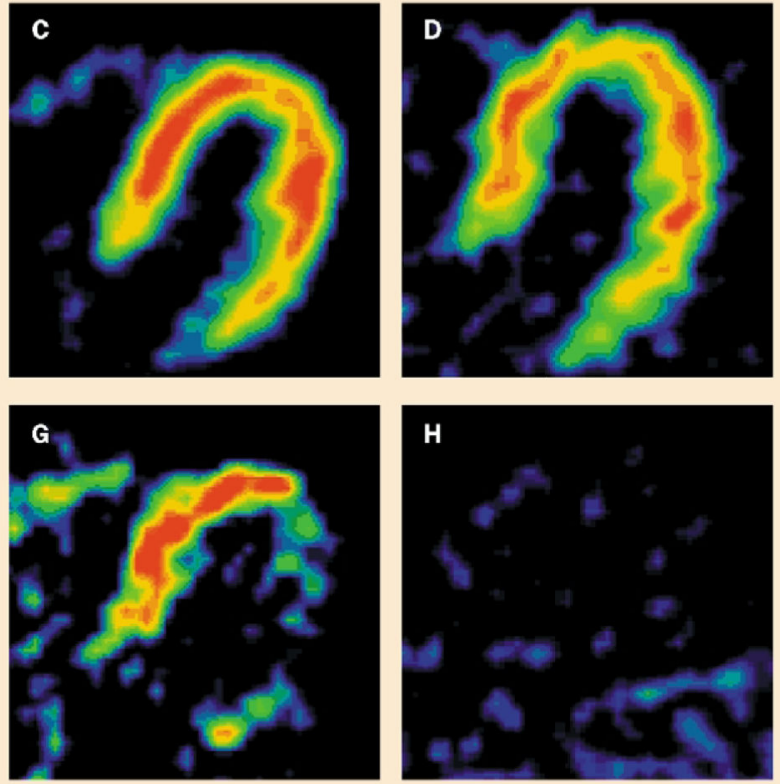

Figure 7.

Cardiac PET scans in patients with PD without orthostatic hypotension. Top: nitrogen-13labelled ammonia perfusion scans. Bottom: ${ }^{18} \mathrm{~F}$-dopa sympathoneural scans. Of 27 patients very few had entirely normal ${ }^{18} \mathrm{~F}$-dopa radioactivity $(\mathrm{A}, \mathrm{E})$. Localised decreases were common (B,F and C,G), and about half had decreased ${ }^{18} \mathrm{~F}$-dopa radioactivity throughout the left ventricular myocardium $(\mathrm{D}, \mathrm{H})$. 


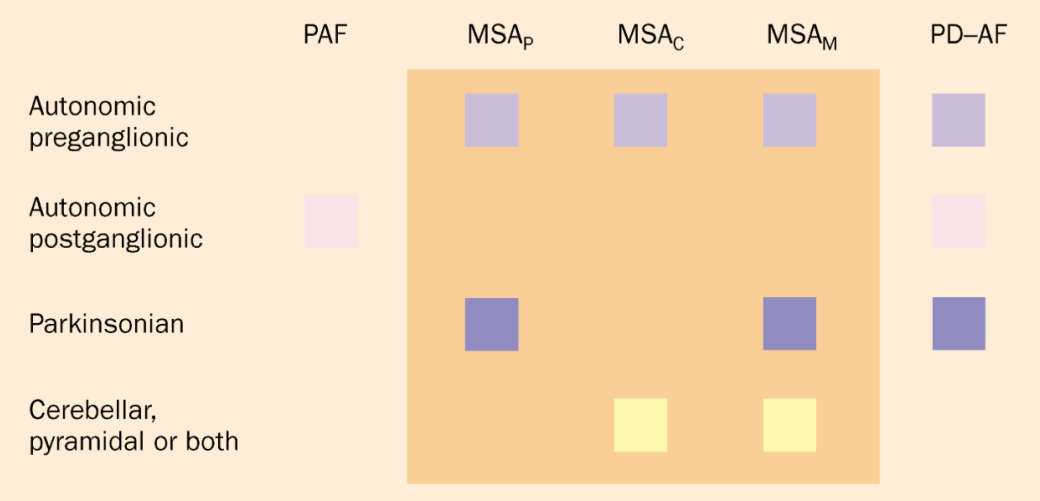

Figure 8

. Proposed pathophysiological classification of primary chronic autonomic failure.

According to this schema, PD with autonomic failure (PD-AF) features a postganglionic, sympathetic, noradrenergic lesion, whereas the parkinsonian form of multiple system atrophy $\left(\mathrm{MSA}_{\mathrm{P}}\right)$ does not. 